\begin{tabular}{l|l|l} 
Jurnal Eksplorasi Akuntansi & ISSN : 2656-3649 (Online) \\
Vol. 1, No 4, Seri C, November 2019, Hal 1949-1967 & http//jea.ppj.unp.ac.id/index.php/jea/issue/view/16
\end{tabular}

\title{
PENERAPAN MODEL UTAUT (UNIFIED THEORY OF ACCEPTANCE AND USE OF TECHNOLOGY) UNTUK MEMAHAMI NIAT DAN PERILAKU AKTUAL PENGGUNA GO-PAY DI KOTA PADANG
}

\author{
Mutiara Indah ${ }^{1}$, Henri Agustin ${ }^{2}$ \\ ${ }^{1}$ Alumni Jurusan Akuntansi Fakultas Ekonomi, Universitas Negeri Padang \\ ${ }^{2}$ Jurusan Akuntansi Fakultas Ekonomi, Universitas Negeri Padang \\ *Korespondensi: mutiaraindah3968@gmail.com
}

\begin{abstract}
This study aims to find evidence that the model UTAUT (Unified Theory of Acceptance and Use of Technology) is a conceptual framework to explain the acceptance and use of Go-Pay as one of the mobile payment services in the city of Padang. The data used in this research is primary data obtained by distributing a questionnaire online. This study using purposive sampling with a sample of 150 respondents who have used Go-Pay.Analysis of the data used in this research is Structural Equation Modeling (SEM). Data analysis techniques using SmartPLS ver.3.2.8 processed. This study found evidence that performance expectancy, social influence and positive effect on behavioral intention; facilitating condition and behavioral intention to use behavior has a positive effect, while the effort expectancy negatively affect behavior intention.
\end{abstract}

Keywords: Mobile Payment; Go-Pay; UTAUT; Padang City

\section{How to cite (APA $6^{\text {th }}$ style)}

Indah, M. \& Agustin, H. (2019). Penerapan Model UTAUT (Unified Theory of Acceptance and Use of Technology) Untuk Memahami Niat dan Perilaku Aktual Pengguna Go-Pay di Kota Kadang. Jurnal Eksplorasi Akuntansi, 1(4), Seri C, 1949-1967.

\section{PENDAHULUAN}

Pengguna internet di Indonesia semakin meningkat di setiap tahunnya seiring dengan perkembangan teknologi informasi yang mengalami kemajuan dengan kecepatan yang tinggi dalam beberapa tahun terakhir. Survei yang dilakukan oleh Asosiasi Penyelenggara Jasa Internet Indonesia (APJII) pada tahun 2017 menunjukkan jumlah pengguna internet di Indonesia mencapai 143,26 juta jiwa dari total 262 juta jiwa populasi penduduk di Indonesia. Perkembangan teknologi informasi yang sangat cepat merubah pola gaya hidup masyarakat menjadi semakin bergantung pada kehadiran teknologi informasi yang mempermudah segalanya menjadi lebih efektif, efisien, dan dinilai lebih ekonomis dibanding dengan gaya hidup sebelum adanya teknologi informasi (Suwandi \& Elvira, 2018).

Kemajuan teknologi telah memungkinkan adanya berbagai fungsi baru untuk perangkat mobile yang mendukung beberapa jasa layanan keuangan seperti pembayaran tagihan, transfer ke rekening, pembayaran jarak jauh untuk pembelian barang dan jasa serta untuk isi ulang saldo (Oliveira et al., 2016; Kim et al., 2010). Pertumbuhan teknologi internet telah merevolusi sistem pembayaran tradisional. Masyarakat sekarang dapat melakukan berbagai transaksi barang dan 
jasa menggunakan metode baru, bukan metode tradisional uang tunai dan cek. Fenomena pembayaran cashless ini dikenal sebagai e-payment. Sistem e-payment memungkinkan masyarakat dapat melakukan pembayaran melalui internet tanpa menggunakan uang tunai. Sistem e-payment memiliki beberapa sifat yang meliputi: kenyamanan, keamanan, transparansi, dan penghematan biaya transaksi (Gholami et al., 2010). Sistem e-payment meliputi kartu debit dan kredit, transfer dana elektronik, dan sistem pembayaran mobile (Mobile payment) (Wenner et al., 2017). Teknologi informasi yang semakin berkembang memungkinkan masyarakat dapat dengan mudah melakukan transaksi pembayaran hanya dengan menggunakan smartphone dan jaringan internet melalui suatu aplikasi layanan pembayaran yang kemudian kita kenal dengan istilah mobile payment. Metode mobile payment yang cashless dapat meningkatkan inklusi keuangan (Wenner et al., 2017) karena mobile payment memperkecil hambatan bagi masyarakat dalam mengakses layanan jasa keuangan, sehingga masyarakat dapat dengan mudah melakukan transaksi pembayaran kecil (Micropayment) tanpa menggunakan uang tunai (Usman, 2017; Karnouskus, 2004).

Pham \& Ho (2015) dalam Oliveira et al., (2016) mengatakan bahwa mobile payment memungkinkan masyarakat menghilangkan kebutuhan untuk menggunakan uang tunai sehingga metode pembayaran mobile payment ini dapat membantu pemerintah dalam mensukseskan program Gerakan Nasional Non Tunai (GNNT) yang telah dicanangkan pada tahun 2014. Keuntungan menggunakan mobile payment diantaranya mempermudah proses transaksi, peningkatan efisiensi, keamanan, dan aksesibilitas. Mobile payment membuat proses pembayaran lebih cepat, lebih aman, dan praktis (Wenner et al., 2017). Masyarakat dapat memanfaatkan layanan mobile payment untuk membayar transaksi kecil dimana pun mereka berada dengan menggunakan smartphone, jaringan internet, dan alat pembayaran berupa uang elektronik berbasis server (Usman, 2017; Karnouskus, 2004; dan Y., Huwaydi et al., 2018).

Fenomena penggunaan mobile payment yang begitu masif telah menyebabkan sejumlah akademisi melakukan riset untuk memahami mobile payment, diantaranya adalah Karnouskus (2004), Chen (2008), Kim et al., (2010), Liébana-Cabanillas et al., (2014), Liu \& Pham (2016), Daştan \& Cem (2016), Oliveira et al., (2016), dan Cao \& Xiaofei (2019). Riset mengenai mobile payment di Indonesia diantaranya Siri et al., (2017), Priyono (2017), Y. Huwaydi et al., (2018), dan Karim (2018). Masifnya penggunaan mobile payment juga terjadi di Indonesia, namun ternyata masih minim riset yang membahas mengapa masyarakat dapat dengan mudah menerima dan menggunakan mobile payment sebagai salah satu aplikasi layanan pembayaran mobile.

Riset yang telah ada menunjukkan bahwa mayoritas peneliti masih menggunakan teori lama, yakninya TAM (Technology Acceptance Model). Sementara menurut penulis lebih baik menggunakan teori baru karena lebih mampu menggambarkan secara luas bagaimana perilaku seseorang terhadap penerimaan teknologi baru. Dalam model-model dasar penerimaan oleh pengguna (user acceptance) terhadap suatu teknologi yang telah dikembangkan, niat menggunakan (behavioural intention) menjadi konstruk perantara dari persepsi atas penggunaan teknologi dan penggunaan aktual teknologi. Peran behavioural intention sebagai prediktor use behaviour telah diterima secara luas dalam berbagai model penerimaan pengguna teknologi. Behavioural Intention didefinisikan sebagai ukuran kekuatan niat seseorang untuk melakukan perilaku tertentu, atau dengan kata lain, behavioural intention adalah seberapa besar keinginan seseorang dalam mengupayakan penggunaan teknologi dalam suatu lingkungan untuk mendukung kinerjanya. Behavioural intention dapat mengukur kemungkinan bahwa konsumen akan bertindak dengan cara tertentu di masa depan, seperti membeli/menggunakan produk lagi dan merekomendasikan kepada orang lain. (Venkatesh et al., 2012). 
Perilaku aktual pengguna (use behaviour) didefinisikan sebagai perasaan positif atau negatif individu dalam menggunakan suatu teknologi dengan frekuensi penggunaan aplikasi sebagai indikatornya. Intensitas atau frekuensi penggunaan dan interaksi antara pengguna dengan teknologi menunjukkan kemudahan penggunaan teknologi. Suatu teknologi yang sering digunakan menunjukkan bahwa teknologi tersebut lebih dikenal, lebih mudah dioperasikan, dan lebih mudah digunakan. Kemudahan penggunaan akan mengurangi usaha baik waktu dan tenaga pada pengguna dalam mempelajari seluk beluk bertransaksi melalui teknologi (Venkatesh et al., 2012).

Layanan mobile payment yang beredar di Indonesia cukup banyak, namun berdasarkan survei yang dilakukan oleh Jakpat pada tahun 2018, ternyata penggunaan layanan mobile payment oleh masyarakat Indonesia didominasi oleh Go-Pay, kemudian Mobile banking di posisi kedua, dan OVO di posisi ketiga. Hal yang menarik disini adalah bahwa Go-Pay telah berhasil menjadi brand mobile payment terfavorit di tahun 2017 (MDI, 2017) dan di tahun 2018 (Jakpat, 2018).

Penelitian ini menggunakan Unified Theory of Acceptance and Use of Technology (UTAUT). Teori ini merupakan penyempurnaan dari teori penerimaan teknologi yang yang telah ada sebelumnya. UTAUT dikembangkan oleh Venkatesh et al., (2003) untuk menjelaskan bagaimana perilaku pengguna terhadap teknologi informasi (Venkatesh et al., 2003). UTAUT merupakan penyempurnaan dari delapan teori penerimaan sistem informasi yang telah ada, yaitu theory of reasoned action (TRA), the Technology Acceptance Model (TAM), motivational models (MM), theory of planned behavior (TPB), combined TAM and TPB (C-TAMTPB), the model of the PC utilization (MPCU), innovation diffusion theory (IDT) dan social cognitive theory (SCT).

UTAUT menunjukkan bahwa niat menggunakan (bahavior intention) dan perilaku aktual pengguna suatu sistem (use behaviour) dipengaruhi oleh harapan kinerja (Performance Expectancy), harapan usaha (effort expectancy), pengaruh sosial (social influence), dan memfasilitasi kondisi (facilitating conditions) (Venkatesh et al., 2003). Harapan kinerja (Performance Expectancy) yaitu tingkat kepercayaan seorang individu bahwa menggunakan sistem dapat membantu dan memberikan keuntungan dalam melakukan pekerjaan. Seseorang akan menggunakan suatu sistem jika sistem tersebut mampu memberikan keuntungan dalam pembayaran yang mereka lakukan sehingga dapat menimbulkan niat untuk menggunakan sistem atau teknologi tersebut.

Harapan usaha (effort expectancy) yaitu tingkat kemudahan terkait penggunaan sistem. Kemudahan dalam mengoperasikan sistem dapat mempengaruhi niat seseorang untuk menggunakan sistem atau teknologi. Seseorang akan menggunakan suatu sistem jika mereka merasa sistem tersebut dapat dipahami dengan mudah. Pengaruh sosial (Social Influence) yaitu pentingnya lingkungan sosial dalam mempengaruhi dan meyakinkan seorang individu untuk juga menggunakan sistem baru. Hal ini berarti bahwa salah satu yang mempengaruhi niat seseorang dalam menggunakan sistem adalah jika mendapat anjuran dari orang-orang di sekitarnya, terutama orang terdekatnya. Memfasilitasi kondisi (Facilitating Conditions) merupakan tingkat kepercayaan seorang individu terhadap ketersediaan infrastruktur untuk mendukung penggunaan sistem (Venkatesh et al., 2003). Hal ini berarti bahwa untuk menggunakan suatu sistem diperlukan adanya infrastruktur dan teknis yang memadai seperti smartphone berbasis android, pulsa data, dan jaringan internet.

UTAUT telah banyak digunakan dalam literatur di atas tahun 2010 baik di dalam maupun luar negeri guna memahami penerimaan terhadap produk sistem informasi yang tidak wajib 
(Voluntary). Penelitian dari dalam negeri beberapa diantaranya yaitu digunakan oleh Bendi \& Sri (2013) dalam penelitiannya untuk memahami perilaku pengguna sistem informasi akademik di Sekolah Tinggi Teknik Musi, Palembang menyatakan bahwa harapan kinerja, harapan usaha, dan memfasilitasi kondisi berpengaruh terhadap niat menggunakan, sedangkan pengaruh sosial tidak berpengaruh terhadap niat menggunakan.

Penulis mencoba mengkaitkan fenomena mengapa masyarakat Indonesia sangat antusias menggunakan layanan mobile payment khususnya Go-Pay dengan menggunakan UTAUT karena berdasarkan penelusuran yang telah dilakukan penulis, riset yang telah dilakukan oleh beberapa peneliti terdahulu belum ada yang menggunakan UTAUT untuk memahami penerimaan masyarakat terhadap penggunaan mobile payment di Indonesia. Venkatesh et al., (2003) dalam penelitiannya menyatakan bahwa model UTAUT terbukti berhasil hingga $70 \%$ varian dalam menentukan niat berperilaku pengguna teknologi informasi dibandingkan teori lainnya sehingga peneliti yakin UTAUT mampu membantu peneliti untuk memahami niat dan perilaku aktual pengguna Go-Pay di Kota Padang.

Peneliti tertarik untuk melakukan penelitian ini berdasarkan latar belakang diatas dengan judul "Penerapan Model UTAUT (Unified Theory of Acceptance and Use of Technology) untuk Memahami Niat dan Perilaku Aktual Pengguna Go-Pay di Kota Padang”.

\section{REVIU LITERATUR DAN HIPOTESIS PENELITIAN}

\section{UTAUT (Unified Theory of Acceptance and Use of Technology)}

UTAUT (Unified Theory of Acceptance and Use of Technology) merupakan teori yang banyak diadopsi untuk melakukan penelitian penerimaan pengguna (user acceptance) terhadap suatu teknologi informasi. UTAUT dikembangkan oleh Venkatesh, et al., (2003) dengan menggabungkan delapan teori penerimaan teknologi terkemuka menjadi satu teori. Delapan teori tersebut yaitu theory of reasoned action (TRA), the Technology Acceptance Model (TAM), motivational models (MM), theory of planned behavior (TPB), combined TAM and TPB (CTAMTPB), the model of the PC utilization (MPCU), innovation diffusion theory (IDT) dan social cognitive theory (SCT). Penggabungan tersebut dilakukan untuk memperbaiki kelemahan yang ada pada teori-teori sebelumnya, dan karena adanya kesamaan antar satu konstruk dalam satu model dan model lainnya. Model ini mempelajari pengaruh dari sejumlah variabel eksternal (Harapan kinerja, harapan usaha, pengaruh sosial, dan memfasilitasi kondisi) terkait dengan niat menggunakan (Behavioural intention), yang pada akhirnya berpengaruh terhadap perilaku aktual pengguna (Use behaviour) itu sendiri.

Hasil dari penggabungan teori tersebut memunculkan empat konstruk baru yaitu harapan kinerja (performance expectancy), harapan usaha (effort expectancy), pengaruh sosial (social influence), dan memfasilitasi kondisi (facilitating condition). Harapan kinerja (Performance expectancy) adalah suatu tingkat dimana seseorang mempercayai dengan menggunakan teknologi akan membanu orang tersebut untuk memperoleh keuntungan kinerja pada pekerjaan/aktivitasnya (Venkatesh et al., 2003). Harapan kinerja (Performance expectancy) merupakan gabungan dari variabel-variabel yang diperoleh dari model penelitian sebelumnya tentang model penerimaan dan penggunaan teknologi yaitu Perceived Usefulness (TAM), Extrinsic motivation (MM), Job Fit, Relative (MPCU), dan Outcome Expectations (SCT)

Harapan usaha (Effort expectancy) merupakan tingkat kemudahan terkait dengan penggunaan sistem informasi (Venkatesh et al., 2003). Harapan usaha (Effort expectancy) merupakan gabungan dari variabel-variabel yang diperoleh dari model penelitian sebelumnya tentang model penerimaan dan penggunaan teknologi yaitu perceived ease of use (TAM), 
complexity (MPCU), dan ease of use (IDT). Pengaruh sosial (social influence) diartikan sebagai tingkat dimana seorang individu menganggap bahwa orang lain meyakinkan dirinya bahwa dia harus menggunakan teknologi tersebut. Pengaruh sosial dibentuk dari Subjective norm(TRA, TAM, TPB), Social factors (MPCU), dan Image (IDT). Memfasilitasi kondisi (facilitating conditions) merupakan sejauh mana seseorang percaya bahwa infrastruktur teknis yang ada dapat mendukung penggunaan sebuah sistem atau teknologi. Memfasilitasi kondisi dibentuk dari Perceived behavioural control (TPB dan C-TAM-TPB), Facilitating condition (MPCU), Compatibility (IDT).

\section{Mobile Payment}

Dahlberg et al., (2008) dalam Oliveira et al, (2016), Karnouskus (2004), Kim \& Lee (2010) dan Liu \& Pham (2016) menggambarkan mobile payment sebagai pembayaran untuk barang, jasa, dan tagihan dengan perangkat mobile seperti smartphone, perangkat personal computer, atau personal digital assistant. Metode pembayaran mobile payment digunakan untuk melakukan transaksi pembayaran kecil (Micropayment) tanpa menggunakan uang tunai (Cashless) (Usman, 2017; Karnouskus, 2004). Keuntungan melakukan transaksi pembayaran dengan mobile payment menurut Y., Huwaydi et al., (2018) adalah kemudahan, karena pengguna dapat melakukan transaksi pembayaran hanya dengan menggunakan smartphone dan jaringan internet sehingga pengguna tidak perlu membawa uang tunai.

Metode mobile payment yang cashless dapat meningkatkan inklusi keuangan (Wenner et al., 2017) karena mobile payment memperkecil hambatan bagi masyarakat dalam mengakses layanan jasa keuangan, sehingga masyarakat dapat dengan mudah melakukan transaksi pembayaran kecil (Micropayment) tanpa menggunakan uang tunai (Usman, 2017; Karnouskus, 2004). Pham \& Ho (2015) dalam Oliveira et al., (2016) mengatakan bahwa mobile payment memungkinkan masyarakat menghilangkan kebutuhan untuk menggunakan uang tunai sehingga metode pembayaran mobile payment ini dapat membantu pemerintah dalam mensukseskan program Gerakan Nasional Non Tunai (GNNT) yang telah dicanangkan pada tahun 2014. Yusuf \& Kurniawan, (2012) memaparkan bahwa mobile payment dapat mengatasi masalah ketidaktepatan waktu penerimaan pelunasan piutang dari pelanggan karena mobile payment menggunakan sistem yang dirancang untuk mengendalikan penerimaan kas dari piutang pelanggan sehingga perusahaan mampu mengurangi permasalahan yang sebelumnya terjadi dan dapat dengan mudah mengendalikan aliran kas masuk dan menghitung pendapatan agar operasional perusahaan dapat berjalan lancar.

Mobile payment menggunakan uang elektronik dengan karakteristik prepaid software, yaitu mekanisme pemindahan uang dengan disetor terlebih dahulu kepada penerbitnya dan kemudian tersimpan pada suatu media server (hard drive) yang terdapat pada perangkat ponsel sehingga dapat digunakan untuk melakukan pembayaran kepada merchant tertentu yang bekerja sama dengan penerbit uang elektronik tersebut. Nilai uang elektronik akan berkurang ketika pemegang uang elektronik melakukan pembayaran atau transfer dana (Usman, 2017).

Layanan mobile payment yang ada di Indonesia diterbitkan oleh bank dan lembaga selain bank (LSB). Layanan mobile payment yang diterbitkan bank diantaranya, CIMB Niaga, Mandiri e-cash, (Usman, 2017); Flazz BCA, Brizzi, BCA Sakuku (Jakpat, 2018). Lembaga selain bank menerbitkan layanan mobile payment diantaranya Go-pay, OVO, Tcash, Paytren, XL Tunai, Paypro, dan lain-lain (Jakpat, 2018). Kelebihan dari melakukan transaksi pembayaran dengan mobile payment diantaranya adalah kemudahan pembayaran tanpa menggunakan uang kembalian, menghilangkan adanya risiko salah hitung, dapat lebih berhemat karena banyaknya 
promosi diskon yang didapatkan, dan kemudahan dalam pengisian saldo (Tionaomi, 2018). Hal yang harus dicatat bahwa meskipun terdapat kelebihan dalam sistem pembayaran dengan mobile payment, ditemukan juga beberapa kekurangan/kelemahan yaitu diantaranya kurangnya infrastruktur yang mendukung beroperasinya mobile payment dan koneksi internet yang tidak stabil sehingga dapat menghambat transaksi pembayaran (Wenner et al.,). Ketidakpahaman masyarakat mengenai mobile payment juga menjadi salah satu hambatan dalam penggunaan mobile payment karena ketidaktahuan masyarakat mengenai mobile payment membuat mereka tidak memiliki kepercayaan untuk melakukan transaksi menggunakan sistem mobile payment tersebut.

\section{Pengaruh Harapan Kinerja terhadap Niat Menggunakan Go-Pay}

Venkatesh et al., (2003) mengatakan bahwa harapan kinerja merupakan suatu tingkatan kepercayaan seseorang untuk mencapai keuntungan dalam pekerjaan mereka dengan sistem yang digunakannya. Hal ini dapat diartikan sebagai tingkat dimana masyarakat meyakini bahwa menggunakan Go-Pay akan memberikan keuntungan seperti dalam hal kecepatan, keamanan, dan kenyamanan sehingga seseorang akan merasakan transaksi pembayaran menjadi lebih efektif, efisien dan ekonomis dibanding dengan pembayaran tunai. Keuntungan tersebut dapat menimbulkan niat seseorang untuk menggunakan Go-Pay sebagai layanan mobile payment.

Menggunakan layanan mobile payment untuk melakukan transaksi pembayaran tagihan listrik dan BPJS Kesehatan melalui menu Go-Bills dengan smartphone akan lebih mempercepat proses pembayaran dibanding dengan menggunakan metode pembayaran seperti biasa karena pengguna tidak perlu pergi ke loket pembayaran dan mengantri untuk dilayani. Melakukan transaksi pembayaran tagihan dengan menggunakan Go-pay juga dapat mengurangi risiko dari kehilangan dan pencurian uang karena pengguna tidak perlu membawa uang tunai untuk membayar tagihannya sehingga pengguna dapat melakukan transaksi pembayaran dengan nyaman (Guo et al., 2015).

Seseorang akan menggunakan suatu sistem jika mereka merasa sistem yang digunakannya mampu memberi rasa aman dan dapat membuat mereka menyelesaikan pekerjaannya dengan lebih cepat. Persepsi keuntungan dalam transaksi pembayaran yang dilakukan tersebut akan mempengaruhi niat seseorang dalam menggunakan layanan mobile payment. Semakin tinggi performance expectancy atau harapan kinerja seseorang terhadap suatu sistem informasi maka akan semakin tinggi pula niat seseorang untuk menggunakan sistem tersebut. Venkatesh et al., (2003) dalam penelitiannya menyatakan bahwa variabel harapan kinerja memiliki pengaruh yang signifikan terhadap niat menggunakan sistem informasi.

Temuan yang sama ditemukan dalam penelitian Sedana \& Wisnu (2009), Bendi \& Sri (2013), Guo et al., (2015), Prasetyo (2017), Dewi \& I Ketut (2017), Agustin dan Mulyani (2016), serta Agustin and Mulyani (2018). Hipotesis penelitian ini berdasarkan hubungan antarvariabel dan temuan riset diatas adalah sebagai berikut:

H1: Harapan kinerja berpengaruh positif terhadap niat menggunakan Go-Pay

\section{Pengaruh Harapan Usaha terhadap Niat Menggunakan Go-Pay}

Variabel ini dapat diartikan sebagai tingkat kemudahan penggunaan sistem informasi yang dapat mengurangi upaya bagi seseorang dalam melakukan suatu pekerjaan (Venkatesh et al., 2003). Kemudahan penggunaan tersebut dapat meningkatkan niat seseorang untuk menggunakan GoPay dalam melakukan transaksi pembayaran dibandingkan dengan pembayaran secara tunai. Ketika pengguna merasa bahwa suatu teknologi mudah digunakan dan tidak memerlukan banyak 
usaha, mereka akan mempunyai ekspektasi yang tinggi untuk mendapatkan kinerja yang diharapkan, jika tidak, harapan kinerja mereka akan rendah. Hal ini berarti fitur Go-Pay yang sederhana menjadikan Go-Pay lebih mudah untuk dipahami dan praktis untuk digunakan. Kemudahan penggunaan Go-Pay dalam proses transaksi pembayaran salah satunya adalah pengguna tidak perlu memikirkan mengenai uang kembalian karena pembayaran melalui Go-Pay adalah dengan saldo yang tersimpan dalam akun pengguna sehingga saldo akan berkurang sebesar biaya transaksi yang telah dilakukan.

Semakin tinggi harapan usaha (Effort expectancy) maka semakin tinggi pula niat untuk menggunakan sistem tersebut. Penelitian yang dilakukan oleh Sedana \& Wisnu (2009), Bendi \& Sri (2013), Prasetyo (2017), Rohmadi et al., (2017), Dewi \& I Ketut (2017), Sivathanu (2018), Mohamad \& Salina (2018), Agustin dan Mulyani (2016), Agustin and Mulyani (2018), Amrullah \& Anjar (2018), dan Wang (2018) menyatakan bahwa variabel harapan usaha berpengaruh terhadap niat menggunakan sistem informasi. Hipotesis penelitian ini berdasarkan hubungan antar variabel dan temuan riset adalah sebagai berikut:

H2: Harapan usaha berpengaruh positif terhadap niat menggunakan Go-Pay.

\section{Pengaruh dari Pengaruh Sosial terhadap Niat Menggunakan Go-Pay}

Variabel ini dapat diartikan sebagai tingkat dimana pengaruh lingkungan sekitar (keluarga, kerabat, teman, dan masyarakat) yang menggunakan Go-Pay memberikan dukungan pada seseorang untuk menggunakan layanan mobile payment yang sama. Masyarakat sebagai makhluk sosal lebih mudah terpengaruh oleh orang- orang di sekitarnya, terlebih jika mendapatkan dorongan untuk melakukan sesuatu seperti menggunakan sistem baru (Cao \& Xiaofei, 2019). Hal ini menunjukkan bahwa salah satu faktor dari niat seseorang untuk menggunakan teknologi baru adalah jika mendapat dukungan atau anjuran dari orang terdekatnya.

Hubungan persaudaraan dan pertemanan dapat memberikan dampak yang kuat terhadap niat menggunakan suatu sistem bagi seorang individu seperti ketika seseorang mendapat suatu rekomendasi dari saudaranya untuk melakukan transaksi pembayaran menggunakan mobile payment, maka ia akan dengan lebih mudah menerima rekomendasi tersebut karena ia mempunyai tingkat kepercayaan yang tinggi kepada orang terdekatnya bahwa segala sesuatu yang disarankan oleh orang terdekatnya adalah yang terbaik.

Penelitian yang dilakukan oleh Sedana \& Wisnu (2009), Guo et al., (2015), Prasetyo (2017), Putri \& irfan (2017), Dewi \& I Ketut (2017), Suwandi \& Elvira (2018), Sivathanu (2018), Wang (2018), Agustin dan Mulyani (2016), Agustin and Mulyani (2018), dan Amrullah \& Anjar (2018) menyatakan bahwa variabel pengaruh sosial berpengaruh positif terhadap niat penggunaan sistem informasi. Hipotesis penelitian ini berdasarkan hubungan antarvariabel dan temuan riset adalah sebagai berikut:

H3: Pengaruh sosial berpengaruh positif terhadap niat menggunakan Go-Pay

\section{Pengaruh Kondisi Pemfasilitasi terhadap Perilaku Aktual Pengguna Go-Pay}

Variabel ini diartikan sebagai tingkat dimana seseorang percaya bahwa infrastruktur dan sumber daya tersedia untuk mendukung penggunaan aktual sistem informasi (Venkatesh et al., 2003). Hal ini menunjukkan bahwa penggunaan aktual seseorang dalam menggunakan layanan Go-Pay sebagai layanan mobile payment didukung oleh infrastruktur dan teknis yang memadai seperti smartphone berbasis android, pulsa data, dan jaringan internet. Penggunaan sistem juga mengharuskan pengguna untuk memiliki keterampilan khusus seperti mengoperasikan smartphone berbasis android dan menghubungkannya ke internet. Biaya akses data juga 
diperlukan oleh pengguna saat mengoperasikan sistem. Hal tersebut berarti bahwa pengguna tidak akan menggunakan suatu sistem jika tidak memiliki infrastruktur dan sumber daya seperti finansial dan keterampilan operasional (Amrullah \& Anjar, 2018).

Kondisi pemfasilitasi memiliki hubungan yang langsung dan signifikan terhadap perilaku aktual (Use behaviour) penggunaan sistem informasi (Venkatesh et al., 2003). Hasil yang sama diperoleh oleh Sedana \& Wisnu (2009), Dewi \& I Ketut (2017), Guo et al., (2015), dan Mohamad \& Salina (2018). Hipotesis penelitian ini berdasarkan hubungan antar variabel dan temuan riset adalah sebagai berikut:

H4: Memfasilitasi kondisi berpengaruh positif terhadap perilaku aktual pengguna Go-Pay

\section{Pengaruh Niat Menggunakan terhadap Perilaku Aktual Pengguna Go-Pay}

Tingginya tingkat niat menggunakan (behavioural intention) akan mempengaruhi tingkat penggunaan suatu sistem (Venkatesh et al., 2003). Behavioural intention berarti niat atau keinginan seseorang dalam menggunakan suatu sistem di masa yang akan datang. Seseorang akan memutuskan untuk menggunakan suatu sistem jika terdapat keinginan dalam dirinya untuk menggunakan sistem tersebut. Behavioural intention memiliki hubungan yang langsung dan signifikan terhadap perilaku aktual (Use behaviour) penggunaan sistem informasi (Venkatesh et al., 2003). Peran behavioural intention sebagai prediktor use behaviour telah diterima secara luas dalam berbagai model penerimaan pengguna teknologi. Artinya, tingginya tingkat variabel behavioural intention mencerminkan tingginya tingkat perilaku penggunaan aktual layanan GoPay.

Sedana \& Wisnu (2009), Susafa'ati (2015), dan Dewi \& I Ketut (2017) menemukan bukti empiris yang menyatakan bahwa niat untuk menggunakan (behavioural intention) berpengaruh signifikan tehadap perilaku aktual penggunaan sistem informasi. Hipotesis penelitian ini berdasarkan hubungan antar variabel dan temuan riset adalah sebagai berikut:

H5: Niat menggunakan (behavioural intention) berpengaruh positif terhadap perilaku aktual pengguna Go-Pay

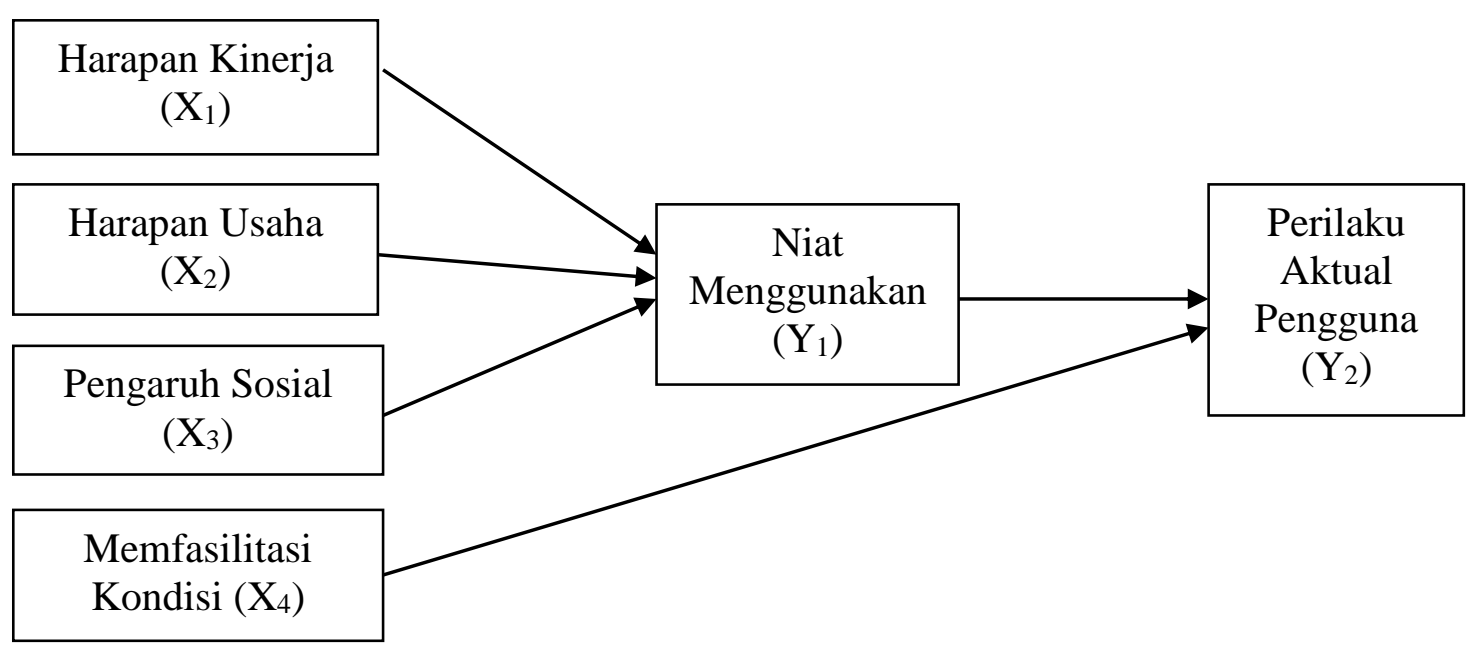

Gambar 1

Kerangka konseptual 


\section{METODE PENELITIAN}

\section{Jenis Penelitian}

Penelitian ini termasuk jenis penelitian kausatif dengan pendekatan kuantitatif. Penelitian kausatif bertujuan untuk mengetahui hubungan dan pengaruh variabel independen terhadap varibel dependen. Subjek penelitian ini adalah pengguna Go-Pay di Kota Padang. Penelitian ini menggunakan purposive sampling dengan jumlah sampel sebanyak 150 responden pengguna GoPay di Kota Padang.

\section{Teknik Pengumpulan Data}

Metode Pengumpulan data dalam penelitian ini adalah penyebaran kuesioner menggunakan form google document yang akan disebar secara online melalui aplikasi whatsapp. Penilaian terhadap setiap pertanyaan dalam kuesioner menggunakan skala likert dengan 4 alternatif pilihan jawaban, yaitu: Sangat Tidak Setuju (STS), Tidak Setuju (TS), Setuju (S), dan Sangat Setuju (SS).

\section{Teknik Analisis Data}

Analisis data dalam penelitian ini menggunakan pendekatan Partial Least Square (PLS). Analisis data dilakukan terhadap 2 hal yaitu outer model dan inner model. Uji Outer Model terdiri dari uji validitas dan reliabilitas. Uji validitas terdiri dari uji validitas konvergen dan validitas diskriminan. Reliabilitas diukur dari nilai composite reliability. Sedangkan uji untuk inner model digunakan untuk koefisien determinan $\left(\mathrm{R}^{2}\right)$ dan Path Coefficient (Uji Hipotesis).

\section{HASIL DAN PEMBAHASAN}

\section{Hasil Uji Outer Model}

Outer model digunakan untuk mengevaluasi hubungan antara indikator dan variabel laten guna menilai validitas dan reliabilitas setiap indikator. Uji validitas konvergen dalam penelitian ini dilakukan dua tahap. Berikut gambar hasil pengujian Validitas Konvergen Tahap 1:

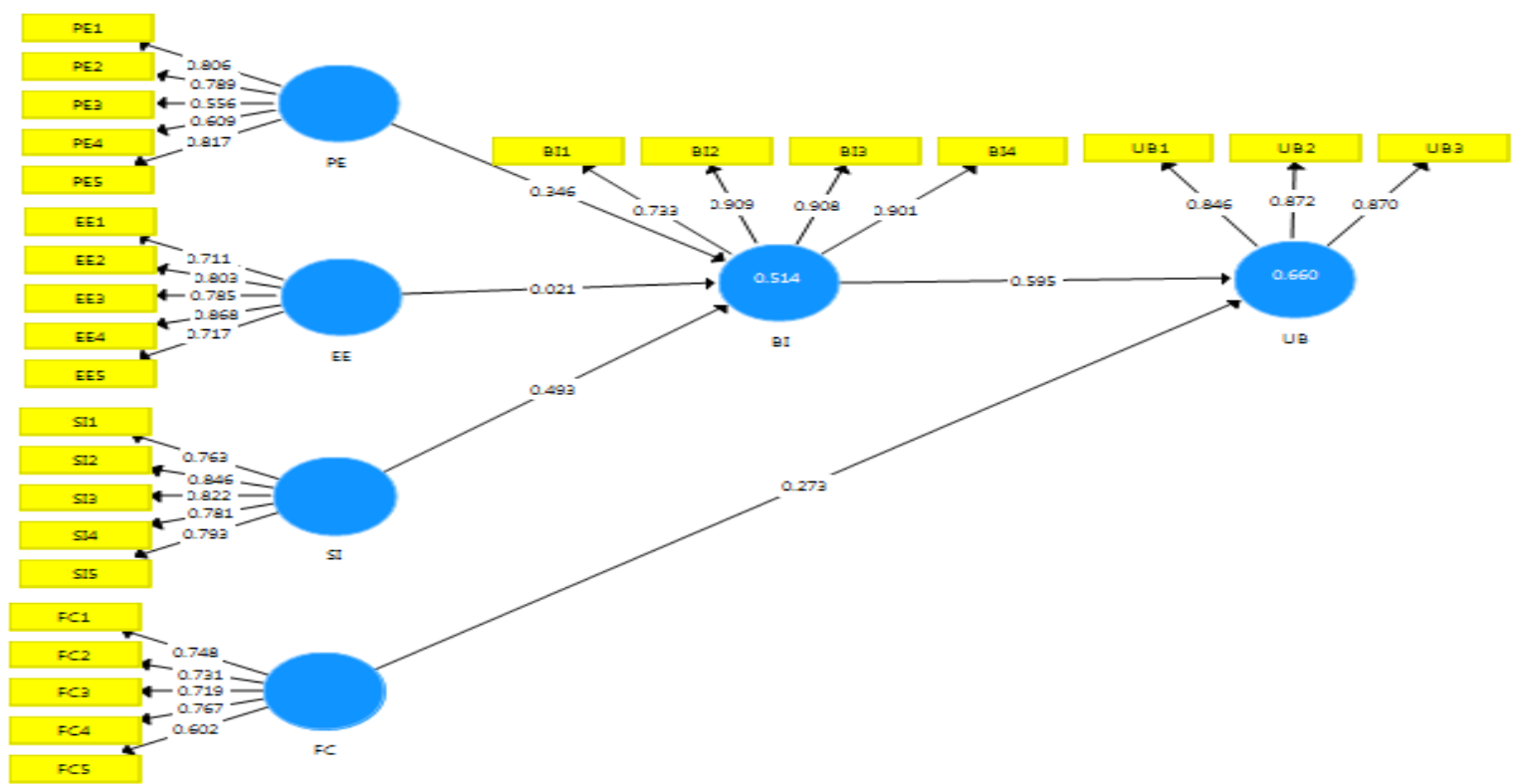

\section{Gambar 2}

Output Uji Validitas Konvergen Tahap 1

Sumber : Olahan data menggunakan software Smart PLS versi 3.2.8 
Dalam penelitian ini tiga indikator yang tidak valid dihapus. Indikator tersebut adalah PE3, PE4, dan FC5. Sesuai dengan Hartono \& Abdillah (2014) indikator yang tidak valid harus dihapus karena indikator tersebut tidak termuat (load) ke konstruk yang mewakilinya. Setelah tiga indikator dihapus, kemudian data diolah kembali dan diperoleh hasil sebagai berikut:

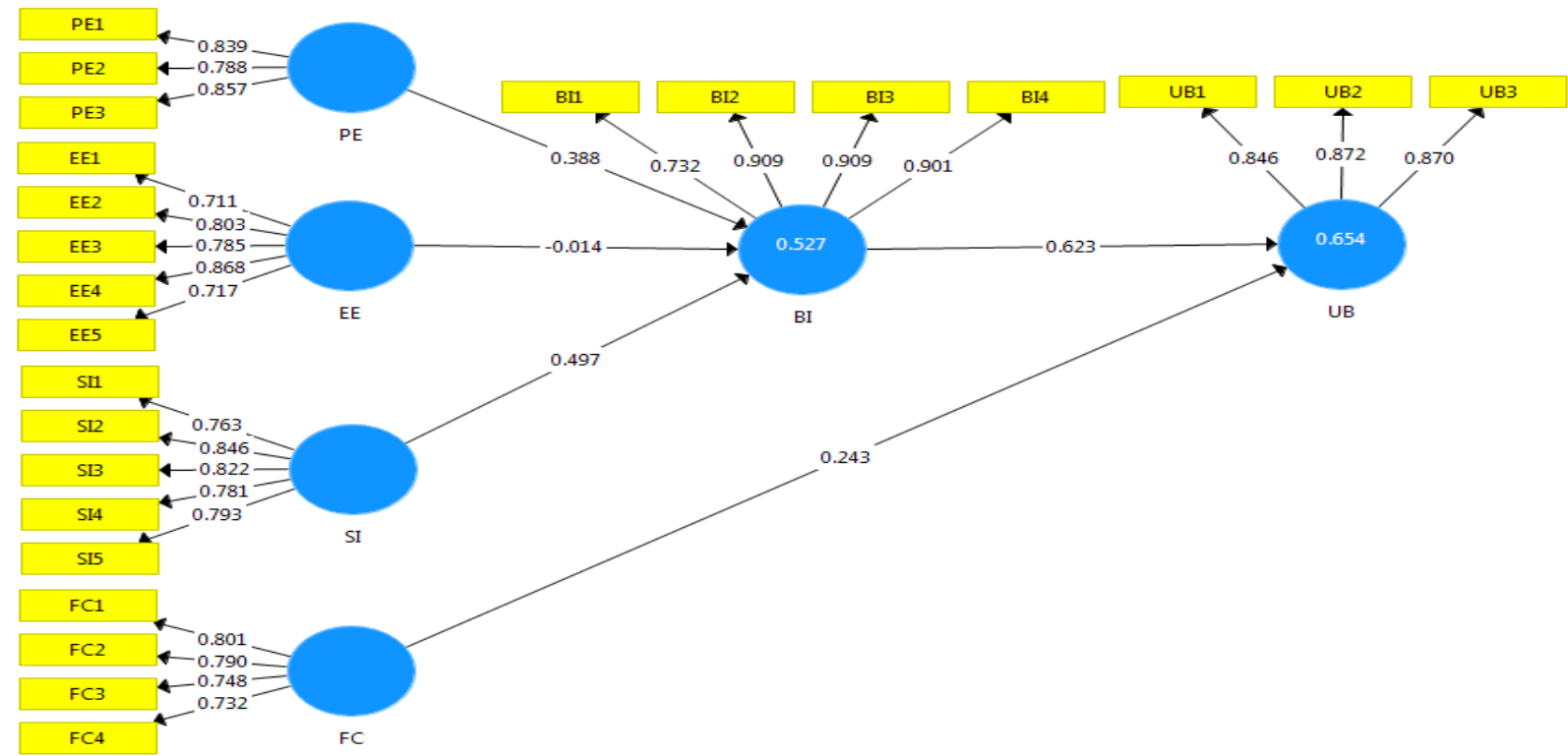

Gambar 3

Output Uji Validitas Konvergen Tahap 2

Sumber : Olahan data menggunakan software Smart PLS versi 3.2.8

Gambar 3 menunjukkan bahwa rule of thumb nilai outer louding semua indikator adalah $>0,7$ sehingga semua indikator dalam penelitian ini telah memenuhi persyaratan. Validitas konvergen pada outer model juga dilihat dari nilai AVE. Nilai AVE menggambarkan besarnya keragaman dari variabel manifest/ indikator yang terdapat pada konstruk. Nilai AVE yang disarankan yaitu minimal 0,5 . Berikut merupakan tabel dari nilai AVE:

Tabel 1

\begin{tabular}{lc}
\hline \multicolumn{1}{c}{ Variabel } & Nilai AVE $(>0,5)$ \\
\hline Performance Expectancy & 0,686 \\
\hline Effort Expectancy & 0,607 \\
\hline Social Influence & 0,642 \\
\hline Facilitating Condition & 0,590 \\
\hline Behaviour Intention & 0,750 \\
\hline Use Behaviour & 0,744 \\
\hline Sumber $:$ Hasil olahan data dengan Smart PLS ver 3.2.8
\end{tabular}

Tabel 1 menunjukkan bahwa seluruh variabel memiliki nilai AVE lebih besar dari 0,5. Hal ini dapat disimpulkan bahwa seluruh variabel pada penelitian ini dapat menjelaskan rata-rata lebih dari setengah varian dari masing-masing indikator yang memiliki validitas konvergen yang baik. Validitas diskriminan dapat dilihat dengan membandingkan akar kuadrat dari nilai AVE 
untuk setiap konstruk dengan nilai korelasi antar konstruk dalam model. Berikut merupakan tabel hasil nilai validitas diskriminan dengan nilai akar kuadrat AVE:

Tabel 2

\begin{tabular}{lllllll}
\hline Variabel & BI & EE & FC & PE & SI & UB \\
\hline Behaviour Intention & $\mathbf{0 , 8 6 6}$ & & & & & \\
\hline Effort Expectancy & 0,525 & $\mathbf{0 , 7 7 9}$ & & & & \\
\hline Facilitating Condition & 0,683 & 0,699 & $\mathbf{0 , 7 6 8}$ & & & \\
\hline Performance Expectancy & 0,563 & 0,759 & 0,612 & $\mathbf{0 , 8 2 8}$ & & \\
\hline Social Influence & 0,635 & 0,492 & 0,675 & 0,373 & $\mathbf{0 , 8 0 2}$ & \\
\hline Use Behaviour & 0,789 & 0,476 & 0,669 & 0,549 & 0,599 & $\mathbf{0 , 8 6 3}$ \\
\hline
\end{tabular}

Sumber : Hasil olahan data dengan Smart PLS ver 3.2.8

Data dari tabel 2 menunjukkan bahwa nilai akar kuadrat dari AVE lebih besar dibandingkan dengan konstruk lainnya. Ini menunjukkan bahwa semua konstruk pada model penelitian yang diestimasi memenuhi kriteria validitas diskriminan yang telah ditentukan.

\section{Uji Indikator Reliability}

Pengujian reliabilitas bertujuan untuk melihat konsistensi dan kestabilan responden dalam menjawab pertanyaan yang terdapat dalam kuesioner. Konstruk dalam penelitian dinyatakan reliabel jika memiliki nilai composite reliability di atas 0,70 .

Tabel 3

\begin{tabular}{lcl}
\hline \multicolumn{1}{c}{ Variabel } & $\begin{array}{c}\text { Composite } \\
\text { reliability }\end{array}$ & Keterangan \\
\hline Performance Expectancy & 0,868 & Reliabel \\
\hline Effort Expectancy & 0,885 & Reliabel \\
\hline Social Influence & 0,900 & Reliabel \\
\hline Facilitating Condition & 0,852 & Reliabel \\
\hline Behaviour Intention & 0,923 & Reliabel \\
\hline Use Behaviour & 0,897 & Reliabel \\
\hline
\end{tabular}

Sumber : Hasil olahan data dengan Smart PLS ver 3.2.8

Berdasarkan tabel diatas diketahui bahwa semua konstruk memiliki nilai composite reliability di atas 0,70 dan cronbach's alpha diatas 0,60. Sehingga dapat disimpulkan bahwa konstruk memiliki reliabilitas yang baik.

\section{Pengujian Model Struktural (Inner Model)}

Evaluasi inner model bertujuan untuk melihat pengaruh langsung atau tidak langsung antar variabel. Evaluasi pada model struktural dapat dilakukan dengan melihat nilai R-Square pada variabel laten endogen dan uji hipotesis dengan meihat nilai t-statistik. 


\section{Tabel 4}

\begin{tabular}{cc}
\hline Variabel & Nilai R Square \\
\hline Behaviour Intention & 0,527 \\
\hline Use Behaviour & 0,654 \\
\hline Sumber : Hasil olahan data dengan Smart PLS ver 3.2.8
\end{tabular}

Tabel 4 menunjukkan bahwa nilai r-square untuk variabel behavioural intention sebesar 0,527. Hal ini mengindikasikan bahwa besarnya pengaruh variabel performance expectancy, effort expectancy, dan social influence menjelaskan sebesar 52,7\% terhadap variabel behavioral intention, sedangkan sisanya 47,3\% dipengaruhi oleh faktor lain. Nilai r-square untuk variabel use behaviour sebesar 0,654, maka variabel facilitating condition dan behavioural intention menjelaskan sebesar $65,4 \%$ variabel use behaviour sedangkan sisanya sebesar 34,6\% dipengaruhi faktor lain. Maka dapat disimpulkan bahwa variabel behavioural intention dan use behaviour dapat dijelaskan oleh faktor-faktor penerimaan dan penggunaan pada penelitian ini.

Pengujian hipotesis pada smartPLS dilakukan dengan prosedur bootstrapping sampel. Kriteria pengujian hipotesis melalui path coefficient dengan melihat output t-statistic dan original sample. Kriteria pengaruh hubungan variabel dinyatakan diterima jika nilai $T$-statistic lebih besar dari pada T-table. Nilai t-table untuk hipotesis dua ekor (two-tailed) dan >1.64 untuk hipotesis satu ekor (one-tailed). Sedangkan untuk melihat arah hubungan hipotesis digunakan nilai original sample, jika nilai original sampel positif berarti arah hubungan hipotesis positif, sedangkan jika nilai original sampel negatif maka arah hubungan hipotesisnya negatif (Hartono \& Abdillah, 2014).

\section{Tabel 5}

\begin{tabular}{ccccc}
\hline $\begin{array}{c}\text { Hubungan } \\
\text { Variabel }\end{array}$ & $\begin{array}{c}\text { t-statistik } \\
>1,96\end{array}$ & $\begin{array}{c}\text { Original } \\
\text { sample }\end{array}$ & $\begin{array}{c}\text { Arah } \\
\text { hubungan }\end{array}$ & Keputusan \\
\hline PE -> BI & 3,453 & 0,388 & Positif & $\mathrm{H}_{1}$ diterima \\
\hline EE -> BI & 0,113 & $-0,014$ & Negatif & $\mathrm{H}_{2}$ ditolak \\
\hline SI -> BI & 6,513 & 0,497 & Positif & $\mathrm{H}_{3}$ diterima \\
\hline FC -> UB & 2,850 & 0,243 & Positif & $\mathrm{H}_{4}$ diterima \\
\hline BI ->UB & 8,337 & 0,623 & Positif & $\mathrm{H}_{5}$ diterima \\
\hline
\end{tabular}

Sumber : Hasil olahan data dengan Smart PLS ver 3.2.8

Data diatas menunjukkan bahwa terdapat empat hipotesis diterima dan satu hipotesis ditolak. Hipotesis yang diterima yaitu $\mathrm{H}_{1}, \mathrm{H}_{3}, \mathrm{H}_{4}$, dan $\mathrm{H}_{5}$, sedangkan hipotesis yang ditolak yaitu $\mathrm{H}_{2}$.

\section{Pembahasan}

Harapan Kinerja (Performance Expectancy) Berpengaruh Positif terhadap Niat Menggunakan (Behavioural intention)

Pengujian hipotesis membuktikan bahwa nilai t-statistik untuk variabel harapan kinerja terpenuhi. Nilai tersebut menunjukkan bahwa tingkat efektivitas, kecepatan, dan kenyamanan 
mampu mempengaruhi niat menggunakan Go-Pay. Hal ini menunjukkan bahwa semakin tinggi tingkat harapan kinerja maka niat menggunakan layanan Go-Pay juga meningkat.

Variabel performance expectancy merupakan konstruk yang penting dalam mempengaruhi niat menggunakan, yang memiliki makna sejauh mana penggunaan teknologi baru dapat memberikan manfaat kepada konsumen dalam melakukan aktifitas tertentu. Berdasarkan hasil pengujian hipotesis 1, Go-Pay mampu memenuhi harapan pada kinerja dan berdampak pada kinerja atau produktifitas yang lebih baik, sehingga dapat memperkuat niat mereka untuk menggunakan Go-Pay. Hal ini mengindikasikan bahwa niat menggunakan Go-Pay bergantung pada efektifitas, kecepatan, dan kenyamanan. Implikasinya adalah bahwa perusahaan harus mempertahankan tingkat performance expectancy-nya agar behavioural intention (niat menggunakan) seseorang semakin tinggi. Langkah yang dapat ditempuh diantaranya adalah dengan memperluas hubungan kerja sama dengan berbagai merchant sehingga pengguna dapat dengan mudah menggunakan Go-Pay dalam melakukan transaksi pembayaran di banyak pusat perbelanjaan yang mereka kunjungi.

Hasil penelitian ini konsisten dengan hasil penelitian Gholami et al., (2010) untuk mengetahui faktor-faktor yang mempengaruhi niat menggunakan e-payment di Nigeria; Wang (2018) dalam penelitiannya mengetahui faktor yang mempengaruhi niat menggunakan aplikasi seluler bagi lansia di Beijing; Guo et al., (2015) dalam penelitiannya mengenai faktor penerimaan Alipay di Cina; Bendi \& Sri (2013) dalam penelitiannya untuk memahami perilaku pengguna sistem informasi akademik di Sekolah Tinggi Teknik Musi di Palembang; Prasetyo (2017) dalam penelitiannya menggunakan model UTAUT untuk memahami penerimaan dan penggunaan Website KKN LPPM UNISI; Dewi \& I Ketut (2017) mengenai faktor penerimaan $e$ filling oleh masyarakat di Denpasar; Agustin dan Mulyani (2016), serta Agustin and Mulyani (2018) mengenai faktor penerimaan dan penggunaan sistem e-learning di kalangan mahasiswa Fakultas Ekonomi UNP serta dosen akuntansi PTN dan PTS di kota Padang, yang menyatakan bahwa performance expectancy memiliki pengaruh positif terhadap behavioural intention.

\section{Harapan Usaha (Effort Expectancy) Berpengaruh Positif terhadap Niat Menggunakan (Behavioural Intention).}

Pengujian hipotesis 2 membuktikan bahwa nilai t-statistik untuk variabel harapan usaha tidak terpenuhi. Angka ini menunjukkan bahwa kemudahan untuk memahami dan menggunakan tidak mampu mempengaruhi niat menggunakan Go-Pay. Variabel harapan usaha (effort expectancy) merupakan konstruk kunci yang berpengaruh pada tahap awal dalam mengadopsi teknologi baru, berkaitan dengan kemudahan dalam mengadopsi teknologi (Venkatesh et al., 2012). Sehingga dapat disimpulkan bahwa pengguna Go-Pay di Kota Padang sudah tidak awam dengan teknologi sehingga effort expectancy tidak menjadi faktor yang mempengaruhi behavioural intention pengguna dalam menggunakan Go-Pay.

Hasil penelitian ini sejalan dengan hasil penelitian Agustin dan Mulyani (2016), serta Agustin and Mulyani (2018) mengenai faktor penerimaan dan penggunaan sistem e-learning di kalangan mahasiswa Fakultas Ekonomi UNP serta dosen akuntansi PTN dan PTS di kota Padang, Suwandi \& Elvira (2018) mengenai faktor yang mempengaruhi penggunaan e-money pada mahassiswa S1 IPB; dan Guo et al., (2015) dalam penelitiannya mengenai faktor penerimaan Alipay di Cina yang menyatakan bahwa variabel effort expectancy tidak memiliki pengaruh terhadap variabel behavioural intention. 


\section{Pengaruh Sosial (social influence) Berpengaruh Positif terhadap Niat Menggunakan (Behavioural Intention)}

Pengujian hipotesis 3 membuktikan bahwa bahwa nilai t-statistik untuk variabel pengaruh sosial terpenuhi. Nilai tersebut menunjukkan bahwa banyaknya orang sekitar yang juga menggunakan produk mobile payment yang sama, adanya rekomendasi dari orang terdekat, dapat menambah rasa percaya diri di lingkungan sosial, dan pengaruh dari media massa mampu mempengaruhi niat menggunakan Go-Pay. Hasil penelitian yang positif menunjukkan bahwa apabila semakin tinggi tingkat pengaruh sosial (social influence) maka niat menggunakan (behavioural intention) layanan Go-Pay juga meningkat.

Pengaruh sosial merupakan persepsi seseorang yang merasa penting untuk orang lain harus menggunakan teknologi baru. Berdasarkan pengertian tersebut, pengaruh sosial pada penelitian ini memiliki arti sejauh mana perilaku orang lain dapat mempengaruhi penggunaan layanan Go-Pay. Maka dapat disimpulkan terdapat pengaruh faktor social influence dalam menggunakan layanan Go-Pay di Kota Padang. Hal ini mengindikasikan bahwa niat menggunakan Go-Pay bergantung pada banyaknya orang sekitar yang juga menggunakan produk mobile payment yang sama, adanya rekomendasi dari orang terdekat, dapat menambah rasa percaya diri di lingkungan sosial, dan pengaruh dari media massa mampu mempengaruhi niat menggunakan Go-Pay.

Implikasinya adalah bahwa perusahaan harus mempertahankan tingkat social influencenya agar behavioural intention (niat menggunakan) seseorang semakin tinggi. Langkah yang dapat ditempuh adalah dengan meningkatkan pengiklanan melalui media massa. Iklan dapat memberi kesan yang baik untuk seseorang bahwa layanan Go-Pay merupakan salah satu metode pembayaran baru yang dapat mempermudah pembayaran untuk beberapa transaksi pembelian barang dan jasa sehingga dapat meningkatkan niat menggunakan seseorang, karena selain dapat mempermudah pembayaran, Go-Pay juga merupakan brand pembayaran terbaru yang cukup dikenal sehingga dengan sendirinya dapat menambah rasa percaya diri seseorang dalam lingkungan sosialnya.

Hasil penelitian ini sejalan dengan hasil penelitian Agustin dan Mulyani (2016), serta Agustin and Mulyani (2018) mengenai faktor penerimaan dan penggunaan sistem e-learning di kalangan mahasiswa Fakultas Ekonomi UNP serta dosen akuntansi PTN dan PTS di kota Padang, Gholami et al., (2010) untuk mengetahui faktor-faktor yang mempengaruhi niat menggunakan e-payment di Nigeria; Wang (2018) dalam penelitiannya mengetahui faktor yang mempengaruhi niat menggunakan aplikasi seluler bagi lansia di Beijing; Guo et al., (2015) dalam penelitiannya mengenai faktor penerimaan Alipay di Cina; Sedana \& Wisnu (2009) untuk mengetahui faktor-faktor yang mempengaruhi penerimaan dan penggunaan Experiential ELearning of Sanata Dharma University (Exelsa); Prasetyo (2017) untuk memahami penerimaan dan penggunaan Website KKN LPPM UNISI; Dewi \& I Ketut (2017) mengenai faktor penerimaan e-filling oleh masyarakat di Denpasar; Suwandi \& Elvira (2018) mengenai faktor yang mempengaruhi penggunaan e-money pada mahassiswa S1 IPB yang menyatakan bahwa pengaruh sosial (social influence) memiliki pengaruh positif terhadap behavioural intention.

\section{Kondisi Pemfasilitasi (Facilitating Condition) Berpengaruh Positif terhadap Perilaku Aktual Pengguna (Use Behaviour)}

Pengujian hipotesis 4 membuktikan bahwa nilai t-statistik untuk variabel memfasilitasi kondisi (facilitating condition) terpenuhi. Nilai tersebut menunjukkan bahwa ketersediaan fasilitas dan sumber daya, dan adanya bantuan dari pihak tertentu (seperti Customer service dan 
driver) mampu mempengaruhi perilaku aktual pengguna Go-Pay. Hal ini menunjukkan bahwa semakin tinggi tingkat facilitating condition maka use behaviour layanan Go-Pay juga meningkat.

Hasil yang diperoleh dalam penelitian ini memiliki makna bahwa kondisi pendukung yang baik akan meningkatkan penggunaan Go-Pay. Artinya apabila pengguna Go-Pay memiliki kendali yang diperlukan untuk menggunakan Go-Pay, pengguna telah disediakan sarana khusus yaitu internet dalam menggunakan Go-Pay, dan pengguna dibantu oleh orang-orang tertentu dalam menggunakan Go-Pay, maka perilaku penggunaan Go-Pay di Kota Padang semakin meningkat.

Implikasinya adalah bahwa perusahaan harus mempertahankan tingkat facilitating condition-nya agar use behaviour semakin tinggi. Langkah yang dapat dilakukan diantaranya adalah lebih gencar dalam melakukan promosi melalui driver Gojek. Salah satu cara mempromosikan Go-Pay kepada pengguna Gojek adalah melalui driver karena selain untuk mengajak pengguna melakukan pembayaran menggunakan Go-Pay, driver Gojek juga dapat membantu memberikan informasi yang diperlukan agar dapat membuat pengguna Gojek lebih yakin untuk menggunakan Go-Pay. Dengan begitu, perusahaan telah memfasilitasi kondisi secara langsung kepada tiap pengguna Gojek untuk menggunakan Go-Pay.

Memfasilitasi kondisi memiliki hubungan yang langsung dan signifikan terhadap perilaku aktual (Use behaviour) penggunaan sistem informasi (Venkatesh et al., 2003). Hasil penelitian ini sejalan dengan Putri \& irfan (2017) mengenai faktor yang mempengaruhi pengguna Gojek di Jakarta; Sedana \& Wisnu (2009) untuk mengetahui faktor-faktor yang mempengaruhi penerimaan dan penggunaan Experiential E-Learning of Sanata Dharma University (Exelsa); Dewi \& I Ketut (2017) mengenai faktor penerimaan $e$-filling oleh masyarakat di Denpasar; Guo et al., (2015) dalam penelitiannya mengenai faktor penerimaan Alipay di Cina; dan Mohamad \& Salina (2018) dalam penelitiannya mengenai faktor penggunaan sistem e-payment oleh sektor keuangan mikro di Malaysia yang menyatakan variabel memfasilitasi kondisi berpengaruh terhadap perilaku aktual pengguna Go-Pay.

\section{Niat Menggunakan (Behavioural Intention) Berpengaruh Positif terhadap Perilaku Aktual Pengguna (use behaviour).}

Pengujian hipotesis 5 membuktikan bahwa nilai t-statistik untuk variabel niat menggunakan (behavioural intention) terpenuhi. Angka ini menunjukkan bahwa semua indikator yang terdapat pada variabel behavioural intention mampu mempengaruhi perilaku aktual pengguna Go-Pay.

Behavioural intention dalam penelitian ini berhubungan dengan niat seseorang menggunakan Go-Pay secara terus menerus. Hasil penelitian yang positif menunjukan bahwa semakin tinggi niat seseorang dalam menggunakan Go-Pay, maka semakin tinggi pula tingkat perilaku aktual penggunaan Go-Pay tersebut. Implikasinya adalah bahwa perusahaan harus mempertahankan tingkat behavioural intention-nya agar use behaviour semakin tinggi. Langkah yang dapat ditempuh diantaranya adalah selalu memperhatikan fitur-fitur/layanan yang ditawarkan agar layanan dapat diperbarui sesuai dengan kebutuhan pengguna; dan tetap memberikan potongan harga kepada pengguna yang melakukan pembayaran dengan Go-Pay.

Behavioural intention memiliki hubungan yang langsung dan signifikan terhadap perilaku aktual (Use behaviour) penggunaan sistem informasi (Venkatesh et al., 2003). Hasil penelitian ini juga sejalan dengan Sedana \& Wisnu (2009) untuk mengetahui faktor-faktor yang mempengaruhi penerimaan dan penggunaan Experiential E-Learning of Sanata Dharma 
University (Exelsa); dan Dewi \& I Ketut (2017) mengenai faktor penerimaan e-filling oleh masyarakat di Denpasar, menemukan bukti empiris yang menyatakan bahwa niat untuk menggunakan (behavioural intention) berpengaruh positif tehadap perilaku aktual penggunaan sistem informasi.

\section{SIMPULAN, KETERBATASAN, DAN SARAN \\ Kesimpulan}

Hasil penelitian mengenai Penerapan model UTAUT (Unified Theory of Acceptance and Use of Technology) untuk memahami niat dan perilaku aktual pengguna Go-Pay di Kota Padang dapat disimpulkan dalam uraian berikut:

1. Variabel harapan kinerja (performance expectancy) $\left(\mathrm{X}_{1}\right)$ berpengaruh positif terhadap niat menggunakan (behavioural intention) pada pengguna Go-Pay di Kota Padang dengan nilai tstatistik 3,662 > 1,96. Artinya Hipotesis 1 penelitian ini diterima.

2. Variabel harapan usaha (effort expectancy) $\left(\mathrm{X}_{2}\right)$ tidak berpengaruh terhadap niat menggunakan (behavioural intention) pada pengguna Go-Pay di Kota Padang. Hasil tersebut terlihat dari nilai t-statistik 0,116 < 1,96. Artinya, Hipotesis 2 penelitian ini ditolak.

3. Variabel pengaruh sosial (social influence) $\left(\mathrm{X}_{3}\right)$ berpengaruh positif terhadap niat menggunakan (behavioural intention) pada pengguna Go-Pay di Kota Padang dengan nilai tstatistik 6,289 > 1,96. Artinya Hipotesis 3 penelitian ini diterima.

4. Variabel memfasilitasi kondisi (facilitating condition) $\left(\mathrm{X}_{4}\right)$ berpengaruh positif terhadap perilaku aktual pengguna (use behaviour) pada pengguna Go-Pay di Kota Padang dengan nilai t-statistik 2,842 > 1,96. Artinya Hipotesis 4 penelitian ini diterima.

5. Variabel niat menggunakan (behavioural intention) $\left(\mathrm{X}_{5}\right)$ berpengaruh positif terhadap perilaku aktual pengguna (use behaviour) pada pengguna Go-Pay di Kota Padang dengan nilai t-statistik 8,302 > 1,96. Artinya Hipotesis 5 penelitian ini diterima.

\section{Keterbatasan}

Penelitian ini memiliki keterbatasan yaitu sebagai berikut:

1. Sampel yang digunakan dalam penelitian ini masih tergolong kecil karena hanya terbatas pada pengguna Go-Pay di Kota Padang.

2. Masih ada variabel lain yang belum digunakan dalam penelitian ini sedangkan variabel tersebut memiliki pengaruh terhadap niat menggunakan (behavioural intention) dan perilaku aktual pengguna (use behaviour)

3. Objek penelitian dalam penelitian ini hanya terbatas pada aplikasi Go-Pay.

\section{Saran}

1. Penelitian selanjutnya diharapkan dapat mengambil sampel lebih besar dan tidak hanya pada pengguna Go-Pay yang berada di Kota Padang saja, agar dapat diperoleh hasil penelitian yang lebih baik.

2. Penelitian selanjutnya diharapkan dapat menggunakan variabel pendukung lainnya yang diduga merupakan faktor yang mempengaruhi penerimaan dan penggunaan Go-Pay.

3. Penelitian selanjutnya disarankan agar dapat menambahkan objek penelitian sehingga tidak hanya pada aplikasi Go-Pay saja, tetapi pada aplikasi mobile payment lainnya. 


\section{DAFTAR PUSTAKA}

Agustin, Henri dan Mulyani, Erly. (2016). Studi Empiris Penerimaan dan Penggunaan ELearning System di Kalangan Mahasiswa Akuntansi Fakultas Ekonomi UNP. Seminar Nasional Aplikasi Teknologi Informasi (SNATI). Yogyakarta. E 17-22.

Agustin, Henri; Mulyani, Erly. (2018). The Acceptance and Use of E-Learning System Among Accounting Lecturers in State and Private Universities in Padang: An Empirical Study Based on UTAUT Model. $1^{\text {st }}$ International Conference On Economics Education, Economics, Business and Management, Accounting and Entrepreneurship (PICEEBA). Padang. 6-13.

Amrullah, A. \& Priyono, A. (2018). Integrasi Aspek Risiko dalam Model Unified Theory Of Acceptance And Use Of Technology Untuk Menganalisis Penerimaan Teknologi Go-Ride. Jurnal Ilmiah Manajemen, 3 (1): 33-49.

APJII. (2017). Infografis: Penetrasi dan Perilaku Pengguna Internet Indonesia. Jakarta: APJII.

Bendi, K.J, \& Andayani, S. (2013). Penerapan Model UTAUT untuk Memahami Perilaku Pengguna Sistem Informasi Akademik. Jurnal HOAQ (High Education of Organization Archive Quality) Teknologi Informasi, 2(1): 50-151.

Cao, Q. \& Niu, X. (2019). Integrating Context-awareness and UTAUT to Explain Alipay User Adoption. International Journal of Industrial Ergonomics, 69: 9-13.

Chen, L. (2008). A Model of Consumer Acceptance of Mobile Payment. International Journal Mobile Communications, 6(1), 32-49.

Daştan, İ. \& Gürler, C. (2016). Factors Affecting the Adoption of Mobile Payment Systems: An Empirical Analysis. Emerging Markets Journal, 6 (1): 16-24.

Dewi, N. P. K. L. R. K, \& Yadnyana, I. K. (2017). Faktor-Faktor yang Mempengaruhi Minat dan Perilaku Penggunaan Sistem E-Filling di Kota Denpasar dengan Model UTAUT. E-Jurnal Akuntansi Universitas Udayana, 21 (3): 2338-2366.

Gholami, R., dkk. (2010). Factors Affecting E-payment Adoption in nigeria. Journal of Electronic Commerce in Organizations, 8 (4): 51-67.

Guo, H., dkk. (2015). Factors Influencing the User Acceptance of Alipay. International Conference on Economy, Management and Education Technology (ICEMET 2015). 344347.

Hartono, J. dan Abdillah, W. (2014). Konsep dan Aplikasi PLS untuk Penelitian Empiris. Yogyakarta: Penerbit BPFE.

Hartono, J.M. (2011). Konsep dan Aplikasi Structural Equation Modeling Berbasis Varian dalam Penelitian Bisnis. Yogyakarta: STIM YKPN.

Huwaydi, Y., dkk. (2018). Analisis Deskriptif Pengguna Go-Pay di Surabaya. Jurnal Teknik ITS (Institut Teknologi Sepuluh Nopember) 7 (1): 2337-3520.

Jakpat. (2018). Mobile Payment in Indonesia (JAKPAT FREE Survey Report 2018). Yogyakarta: Indonesia.

Karim, M. A. (2018). Pengaruh Penerimaan Sistem Pembayaran Go-Pay Mneggunakan TAM (Technology Acceptance Model) Terhadap Intensitas Penggunaan Layanan Go-Jek. Skripsi.

Karnouskus, S. (2004). Mobile Payment: A Journey Through Existing Procedures and Standardization Initiatives. IEEE Communications Surveys \& Tutorials, 6(4): 44-66.

Kim, C., Mirusmonov, M., \& Lee, I. (2010). An Empirical Examination of Factors Influencing the Intention to Use Mobile Payment. Computers in Human Behavior, 26(3): 310-322

Liébana-Cabanillas, F., dkk. (2014). Antecedents of the Adoption of the New Mobile Payment Systems: The Moderating Effect of Age. Computers in Human Behavior, 35: 464-478. 
Liu, G-S \& Tai, P. T. (2016). A Study of Factors Affecting the Intention to Use Mobile Payment Services in Vietnam. Economics World, 4(6): 249-273.

Metra Digital Innovation (MDI). (2018). Mobile Payments in Indonesia: Race to Big data Domination. Jakarta: Indonesia.

Mohamad, S. A. \& Kassim, S. (2018). Examining the Relationship between UTAUT Construct, Technology Awareness, Financial Cost and E-Payment Adoption among Microfinance Clients in Malaysia. Advances in Social Science, Education and Humanities Research. First Aceh Global Conference (AGC 2018), 292: 351-357.

Mulyani, A. (2018). Analisis Penerimaan dan Penggunaan Teknologi Aplikasi Ojek Online Menggunakan Unified Theory of Acceptance and Use Technology. Jurnal Algoritma Sekolah Tinggi Teknologi Garut, 15 (2): 25-30.

Oliveira, T, dkk. (2016). Mobile payment: Understanding the Determinants of Customer Adoption and Intention to Recommend the Technology. Computers in Human Behavior, 61: 404-414.

Prasetyo, D. Y. (2017). Penerapan Model UTAUT dalam Memahami Penerimaan dan Penggunaan Website KKN LPPM UNISI. Jurnal SISTEMASI (Sistem Informasi), 6 (2): 2634.

Priyono, A. (2017). Analisis Pengaruh Trust dan Risk dalam Penerimaan Teknologi Dompet Elektronik Go-Pay. Jurnal Siasat Bisnis, 21 (1): 88-106.

Putri, L. F. S. \& Mahendra, I. (2017). Analisa Faktor- faktor yang Mempengaruhi Penerimaan dan Penggunaan Aplikasi Gojek Menggunakan Unified Theory Of Acceptnce And Use Of Technology. Jurnal Pilar Nusa Mandiri, 13 (1): 136-144.

Rohmadi, dkk. (2017). Evaluasi Sistem Informasi Rumah Sakit untuk Mengetahui Minat Pengguna dengan Metode UTAUT (Studi Kasus RS. Jati Husada Karanganyar). Jurnal INFORMA Politeknik Indonusa Surakarta, 3 (1):1-16.

Sedana, I. G. N \& Wijaya, S. W. (2009). Penerapan Model UTAUT untuk Memahami Penerimaan dan Penggunaan Learning Management System Studi Kasus: Experential ELearning Of Sanata Dharma University. Jurnal Sistem Informasi, 5 (2): 114-120.

Siri, M., Fitriyani, \& Herliana, A. (2017). Analisis Sikap Pengguna Paytren Menggunakan Technology Acceptance Model. Jurnal Informatika, 4(1), 66-75.

Sivathanu, B. (2018). Adoption of Digital Payment Systems in the Era of Demonetization in India. Journal of Science and Technology Policy Management. https://doi.org/10.1108/JSTPM-07-2017-0033. Diakses pada 15 Januari 2019.

Susafa'ati. (2015). Pengukuran Kepuasan Penggunaan Aplikasi LSD Air Freight Cargo dengan Metode UTAUT. Jurnal Pilar Nusa Mandiri, 11 (2): 142-151.

Suwandi, M. A dan Azis, E. (2018). Faktor- faktor yang Mempengaruhi Penggunaan E- Money pada Generasi Millenials (Studi Kasus pada Mahasiswa S1 IPB). E-Proceeding of Management, 5(3): 3104- 3111.

Tionaomi, R. T. (2018). Analisis Pengaruh Fitur Go-Pay Terhadap Permintaan Gojek di Fakultas Ekonomi Universitas Negeri Jakarta. Skripsi.

Usman, R. (2017). Karakteristik Uang Elektronik dalam Sistem Pembayaran. Yuridika, 32 (1): 134-166.

Venkatesh, V., dkk. (2003). User Acceptance of Information Technology: Toward a Unified View. MIS Quarterly, 27 (3): 425-478.

Venkatesh, V., dkk. (2012). Consumer Acceptance and Use Information Technology: Extending The Unified Theory of Acceptance and Use of Technology. MIS Quarterly, 36: 157-178. 
Wang, K. (2018). Research on Influence Factors of the Elderly's Intention to Use Mobile Applications. Advances in Social Science, Education and Humanities Research (ASSEHR), 230: 196- 202.

Wenner, G., dkk. (2017). Organizational Models of Mobile Payment Systems in Low-Resource Environments. Information Technology for Development, 1: 21-25. http://dx.doi.org/10.1080/02681102.2017.131183. Diakses pada 10 Februari 2019.

Yusuf, M., \& Kurniawan, M. (2012). Pengaruh Sistem Pembayaran Listrik Online (Payment Point Online Bank) Terhadap Pengendalian Internal Kas Pada PT. PLN (Persero) DJBB. Jurnal Ekonomi, Bisnis \& Entrepreneurship, 6(1). 51-63. 